\title{
Efficacy of metformin for advanced-stage endometrial cancer: A case report
}

\author{
EMI SATO ${ }^{1}$, KENTARO NAKAYAMA ${ }^{1}$, KOHEI NAKAMURA ${ }^{1}$, NORIYOSHI ISHIKAWA ${ }^{2}$, \\ MASAKO ISHIKAWA ${ }^{1}$, TOSHIKO MINAMOTO ${ }^{1}$, TOMOKA ISHIBASHI ${ }^{1}$ and SATORU KYO ${ }^{1}$ \\ Departments of ${ }^{1}$ Obstetrics and Gynaecology and ${ }^{2}$ Organ Pathology, Shimane University School \\ of Medicine, Izumo, Shimane 6938501, Japan
}

Received October 14, 2016; Accepted December 15, 2016

DOI: $10.3892 /$ mco.2017.1130

\begin{abstract}
The paradigm of obesity, diabetes mellitus and insulin resistance possibly plays a critical role in the pathogenesis of endometrial cancer (EC). Impaired glucose tolerance and insulin resistance may play a direct or facilitating role in the neoplastic transformation of the endometrium, whereas antidiabetic therapy, particularly with metformin, has been suggested to inhibit EC progression. We herein present the case of a patient with EC who received metformin monotherapy due to complications after undergoing surgery. At 45 months after the introduction of metformin treatment, the patient had no complaints and continued receiving metformin without signs of tumor recurrence. As metformin is widely used among diabetic patients and in ongoing clinical trials in cancer patients, the aforementioned results deserve further clinical investigation.
\end{abstract}

\section{Introduction}

Endometrial cancer (EC) is the third most common gynecological malignancy worldwide, after breast and cervical cancers (1). While insulin resistance and diabetes mellitus (DM) may facilitate the initiation and progression of EC, effective DM control has been suggested to prevent or modulate EC (2). Metformin is an oral insulin-sensitizing agent used as first-line therapy for type 2 DM (3). As shown in a recent review, several in vitro and observational studies have evaluated the potential benefits of metformin in the prevention or treatment of gynecological cancers $(4,5)$. In vitro data have demonstrated that metformin administration inhibits the growth and decreases the invasion and metastasis of EC cell lines $(6,7)$. A multi-institutional study recently demonstrated

Correspondence to: Dr Kentaro Nakayama, Department of Obstetrics and Gynecology, Shimane University School of Medicine, 89-1 Enyacho, Izumo, Shimane 6938501, Japan

E-mail:kn88@med.shimane-u.ac.jp

Key words: endometrial cancer, metformin that metformin use was associated with an improvement in the recurrence-free and overall survival of patients with EC (8). We herein describe the case of a patient with EC who was treated with metformin and remained disease-free during a long follow-up period.

\section{Case report}

A 79-year-old woman, gravida 1, para 0, presented with lower abdominal pain. The patient was examined in a gynecological clinic (September, 2012). Magnetic resonance imaging (MRI) revealed a mass sized $\sim 4 \mathrm{~cm}$ in the endometrium (Fig. 1) and computed tomography (CT) revealed two $2-\mathrm{cm}$ peritoneal disseminations (Fig. 2). The carbohydrate antigen-125 level was $53 \mathrm{ng} / \mathrm{ml}$ (normal range, $<35 \mathrm{ng} / \mathrm{ml}$ ), and the carcinoembryonic antigen level was $8.6 \mathrm{ng} / \mathrm{ml}$ (normal range, $<5.0 \mathrm{ng} / \mathrm{ml}$ ). The diagnosis was endometrial adenocarcinoma. The patient had a history of type $2 \mathrm{DM}$ and hypertension, but was not obese (body mass index, $23.6 \mathrm{~kg} / \mathrm{m}^{2}$ ). The HbA1c level (National Glycohemoglobin Standardization Program) was $9.1 \%$, and the patient was treated with oral medications [sulfonylurea and dipeptidyl peptidase-4 (DPP-4) inhibitor].

The patient was referred to the Shimane University Hospital for treatment of the pelvic and abdominal masses, where she underwent modified radical hysterectomy, bilateral salpingooophorectomy, pelvic lymphadenectomy and abdominal mass resection. All identifiable masses were resected. Pathological examination revealed a stage IVB (International Federation of Gynecology and Obstetrics 2008), pT1aN0M1 endometrial serous adenocarcinoma.

Although adjuvant chemotherapy was planned, the postoperative follow-up was complicated by perforation of the digestive tract and severe inflammation of the peritoneum. To control glycemia, insulin was initially used, but it was replaced with metformin (250 $\mathrm{mg}$ once a day) and other oral medications (sulfonylurea and DPP-4 inhibitor) following discharge from the hospital. No further medical treatment was performed.

After being discharged from the hospital, the patient did not exhibit elevated levels of tumor markers or any metastases on CT. At 45 months after the initial metformin treatment, the patient had no complaints and maintained a good quality of life, without signs of tumor progression. 

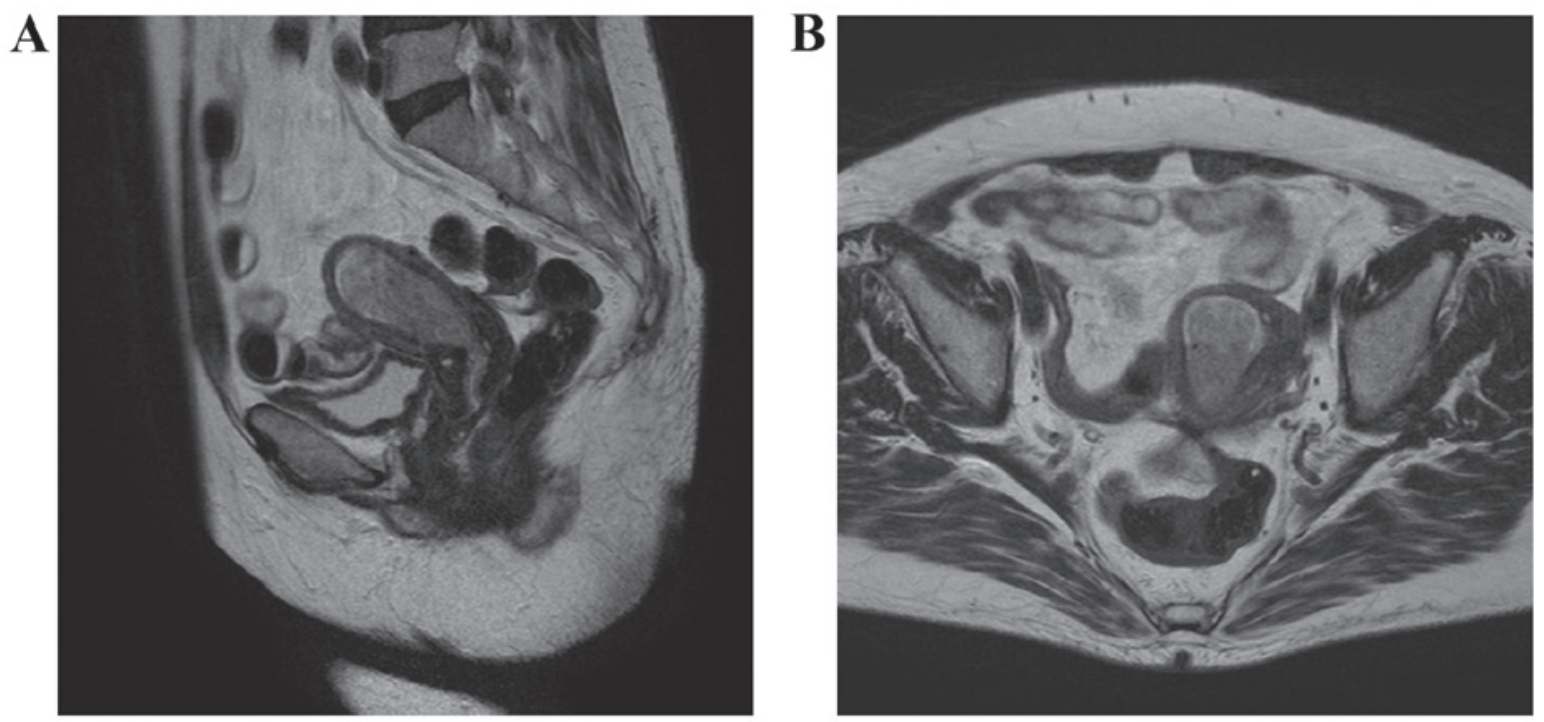

Figure 1. Magnetic resonance image showing the endometrial cancer. Preoperative T2-weighted images: (A) sagittal section and (B) horizontal section
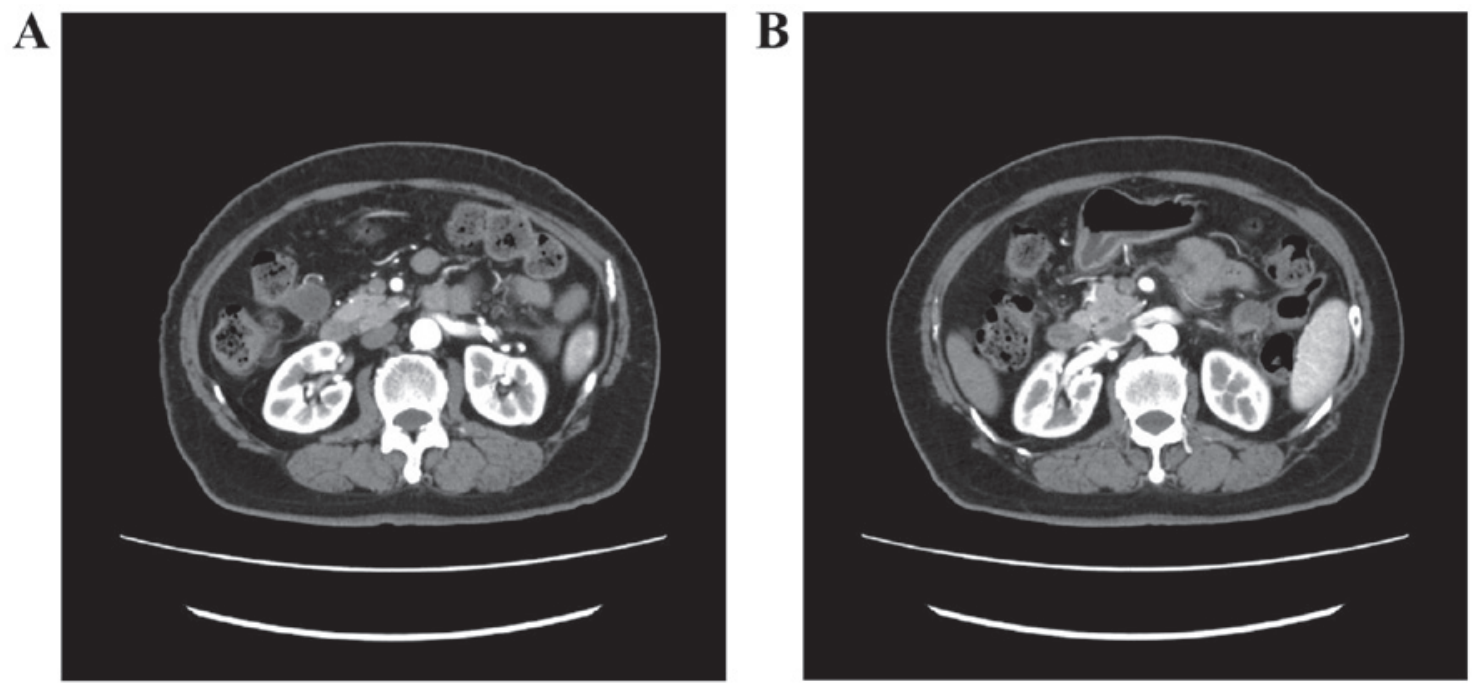

Figure 2. Computed tomographic images showing peritoneal dissemination. (A) Dorsal side of the transverse colon and (B) anterior side of the left kidney.

\section{Discussion}

The mechanism underlying the antitumor effect of metformin is considered to involve the activation of adenosine monophosphate-activated protein kinase and inhibition of the mammalian target of rapamycin, which reduces cell growth (9). Metformin arrests the cell cycle of EC cells, decreases human telomerase reverse transcriptase mRNA expression, and inhibits the phosphorylation of S6RP, resulting in the inhibition of signaling downstream of the mRNA pathway $(10,11)$. Thus, in EC, cell cycle arrest by metformin has been observed in vitro, and inhibition of telomerase activity may be an important mechanism underlying the antitumor activity of this drug (10).

Clinical evidence on the effect of metformin on EC outcome is limited to retrospective data and does not generally account for the effects of multiple covariates, such as pathology, stage and treatment, on clinical outcome (12). It cannot be definitively concluded that patients who receive metformin are less likely to succumb to EC, as metformin may also reduce mortality from other causes (e.g., complications of diabetes and cardiovascular disease) (13).

In the present case, adjuvant chemotherapy and radiotherapy could not be administered, but the patient remained disease-free over a long period of time with metformin therapy alone. The contribution of complete surgical resection to this clinical benefit cannot be ruled out. Moreover, whether this was the natural course of EC in our patient remains unclear. Despite these limitations, this clinical case suggests that metformin is potentially beneficial in the prevention or treatment of EC. This finding deserves further validation in clinical studies (14-16).

\section{References}

1. Siegel R, Ma J, Zou Z and Jemal A: Cancer statistics, 2014. CA Cancer J Clin 64. 9-29, 2014. Erratum in. CA Cancer J Clin 64: 364, 2014. 
2. Zhang Y, Liu Z, Yu X, Zhang X, Lü S, Chen X and Lü B: The association between metabolic abnormality and endometrial cancer: A large case-control study in China. Gynecol Oncol 117: 41-46, 2010.

3. American Diabetes Association: Executive summary: Standards of medical care in diabetes-2014. Diabetes Care 37 (Suppl 1): S5-S13, 2014

4. Febbraro T, Lengyel E and Romero IL: Old drug, new trick: Repurposing metformin for gynecologic cancers? Gynecol Oncol 135: 614-621, 2014

5. Stine JE and Bae-Jump V: Metformin and gynecologic cancers. Obstet Gynecol Surv 69: 477-489, 2014.

6. Tan BK, Adya R, Chen J, Lehnert H, Sant Cassia LJ and Randeva HS: Metformin treatment exerts antiinvasive and antimetastatic effects in human endometrial carcinoma cells. J Clin Endocrinol Metab 96: 808-816, 2011.

7. Cantrell LA, Zhou C, Mendivil A, Malloy KM, Gehrig PA and Bae-Jump VL: Metformin is a potent inhibitor of endometrial cancer cell proliferation-implications for a novel treatment strategy. Gynecol Oncol 116: 92-98, 2010.

8. Ko EM, Walter P, Jackson A, Clark L, Franasiak J, Bolac C, Havrilesky LJ, Secord AA, Moore DT, Gehrig PA, et al: Metformin is associated with improved survival in endometrial cancer. Gynecol Oncol 132: 438-442, 2014.

9. Emami Riedmaier A, Fisel P, Nies AT, Schaeffeler E and Schwab M: Metformin and cancer: From the old medicine cabinet to pharmacological pitfalls and prospects. Trends Pharmacol Sci 34: 126-135, 2013.

10. Ben Sahra I, Laurent K, Loubat A, Giorgetti-Peraldi S Colosetti P, Auberger P, Tanti JF, Le Marchand-Brustel Y and Bost F: The antidiabetic drug metformin exerts an antitumoral effect in vitro and in vivo through a decrease of cyclin D1 level. Oncogene 27: 3576-3586, 2008.
11. Tsuji K, Kisu I, Banno K, Yanokura M, Ueki A, Masuda K, Kobayashi Y, Yamagami W, Nomura H, Susumu N, et al: Metformin: A possible drug for treatment of endometrial cancer. Open J Obstet Gynecol 2: 1-6, 2012.

12. Al Hilli MM, Bakkum-Gamez JN, Mariani A, Cliby WA, Mc Gree ME, Weaver AL, Dowdy SC and Podratz KC: The effect of diabetes and metformin on clinical outcomes is negligible in risk-adjusted endometrial cancer cohorts. Gynecol Oncol 140: 270-276, 2016.

13. Ezewuiro O, Grushko TA, Kocherginsky M, Habis M, Hurteau JA, Mills KA, Hunn J, Olopade OI, Fleming GF and Romero IL: Association of Metformin Use with Outcomes in Advanced Endometrial Cancer Treated with Chemotherapy. PLoS One 11: e0147145, 2016.

14. Amant F, Moerman P, Neven P, Timmerman D, Van Limbergen E and Vergote I: Endometrial cancer. Lancet 366: 491-505, 2005.

15. Mitsuhashi A, Kiyokawa T, Sato Y and Shozu M: Effects of metformin on endometrial cancer cell growth in vivo: A preoperative prospective trial. Cancer 120: 2986-2995, 2014

16. Indraccolo S, Randon G, Zulato E, Nardin M, Aliberti C, Pomerri F, Casarin A and Nicoletto MO: Metformin: A modulator of bevacizumab activity in cancer? A case report. Cancer Biol Ther 16: 210-214, 2015. 